\title{
ECO-EPIDEMIOLOGICAL ASPECTS OF Trypanosoma cruzi, Trypanosoma rangeli AND THEIR VECTOR (Rhodnius pallescens) IN PANAMA
}

\author{
Ana Maria de VASQUEZ, Franklyn E. SAMUDIO, Azael SALDAÑA, Hector M. PAZ \& José E. CALZADA
}

\begin{abstract}
SUMMARY
The eco-epidemiology of T. cruzi infection was investigated in the Eastern border of the Panama Canal in Central Panama. Between 1999 and 2000, 1110 triatomines were collected: 1050 triatomines (94.6\%) from palm trees, 27 (2.4\%) from periurban habitats and 33 (3.0\%) inside houses. All specimens were identified as $R$. pallescens. There was no evidence of vector domiciliation. Salivary glands from $380 \mathrm{R}$. pallescens revealed a trypanosome natural infection rate of $7.6 \%$, while rectal ampoule content from 373 triatomines was $45 \%$. Isoenzyme profiles on isolated trypanosomes demonstrated that $85.4 \%(\mathrm{n}=88)$ were $T$. cruzi and $14.6 \%(\mathrm{n}=$ 15) were T. rangeli. Blood meal analysis from 829 R. pallescens demonstrated a zoophilic vector behavior, with opossums as the preferential blood source. Seroprevalence in human samples from both study sites was less than $2 \%$. Our results demonstrate that $T$. cruzi survives in the area in balanced association with $R$. pallescens, and with several different species of mammals in their natural niches. However, the area is an imminent risk of infection for its population, consequently it is important to implement a community educational program regarding disease knowledge and control measures.
\end{abstract}

KEYWORDS: American trypanosomiasis; Chagas disease; Trypanosoma cruzi; Trypanosoma rangeli; Rhodnius pallescens; Panama.

\section{INTRODUCTION}

The protozoan Trypanosoma cruzi is the etiological agent of Chagas disease, an incurable, chronic, and incapacitating condition afflicting millions of people in Central and South America ${ }^{28}$. The disease is a zoonosis in which the parasite is transmitted to humans through the feces of blood sucking triatomine bugs. Because of a higher risk of exposure to infected triatomines, infection is primarily present among people who live under poor conditions in rural settlements. The extension of urban areas into neighboring forests, the original sylvatic ecotope of the vector, has resulted into the emergence of the infection to periurban areas. Furthermore, rural-urban migration of people has led to the urbanization of an originally rural disease ${ }^{7}$.

Ten different triatomine species have been described from Panama. However, the principal vectors of Chagas disease in the country are Rhodnius pallescens and Triatoma dimidiata ${ }^{12,13} . R$. pallescens is also the vector of Trypanosoma rangeli, a non pathogenic trypanosome transmitted through the saliva of triatomines, that is endemic in Panama. Though with different geographic distribution and with different trypanosome infection rates, a previous study conducted three decades ago demonstrated that both vector species are highly prevalent in certain regions of the country ${ }^{24}$. Nevertheless, there is a lack of recent data regarding triatomine prevalence and its natural infection rates with trypanosomes.
Triatomine species are highly adapted to their natural ecotope. A close association of $R$. pallescens and $T$. dimidiata with palm trees, particularly with the widely distributed "corozo royal palm tree", Attalea butyracea has been observed in Panama ${ }^{25,26}$. Several natural mammal reservoirs for $T$. cruzi have been described in the country, opossums being considered responsible for the maintenance of the sylvatic cycle of the disease $\mathrm{e}^{4,23}$. It must not be overlooked that human activities in the forest interface and within the forested area, including deforestation, may lead to changes in the ecology of the vector, thus affecting the local epidemiology of Chagas disease in the area.

Chagas disease has been described in Panama since $1931^{14}$. A previous seroprevalence survey carried out by SOUSA \& JOHNSON ${ }^{24}$, showed that anti-T. cruzi antibodies were present in several parts of the country with a prevalence ranging from $3.1 \%$ to $21.5 \%$. Since then, no information has been published on the prevalence of human trypanosomiasis in the country. However, evaluation of epidemiological data passively gathered from patients attending National Care Centers during the last decade, suggests an increased morbidity of Chagas disease ${ }^{15}$.

A significant reduction in T. cruzi transmission has occurred in certain South American Cone countries as a result of an aggressive insecticide spraying campaign to eradicate domiciliary vectors ${ }^{22}$. To what extend this experience can be extrapolated to countries with different eco- 


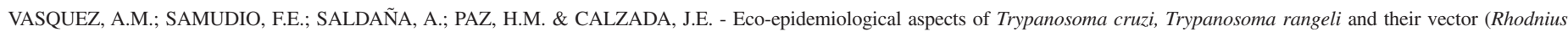
pallescens) in Panama. Rev. Inst. Med. trop. S. Paulo, 46(4):217-222, 2004.

epidemiological situations and where Chagas disease remains a persistent problem, as in the case of Panama, has not been evaluated.

The Ministry of Health of the Republic of Panama is now in the process of defining a National Chagas disease Control Program, which includes free of cost diagnoses and treatment when necessary. Thus, there is an urgent need for recent information so that local authorities may plan new and effective strategies to achieve this goal. Control strategies will strongly depend on a better understanding of the biology of the insect population, as well as on all the various ecological aspects involved in the transmission of T. cruzi within the different regions of the country. An accurate assessment of $T$. cruzi and $T$. rangeli regarding specific hosts, reservoirs and vectors is considered an essential component for new control strategies.

The area selected for the present study is located in the central region of Panama, next to the Canal Reserve Forested Area. Previous studies conducted more than three decades ago, described this region as endemic for $T$. cruzi infection. Due to the increasing number of inhabitants, and therefore to the construction of new facilities, the area has experienced considerable ecological changes. The objective of the present study was to evaluate the present eco-epidemiological situation of T. cruzi infection within these particular sites. Data will provide recent information to the Panamanian government for effective control measures.

\section{MATERIAL AND METHODS}

Study site: A simple non-stratified random survey in 716 different houses (90\% of the total), in the settlements of Buenos Aires $(n=368)$ and Agua Bendita $(\mathrm{n}=348)$, was conducted as part of an ecoepidemiological study on Chagas disease carried out during 1999 and 2000. These two adjacent periurban neighborhoods within the Community of Chilibre are located on the Eastern border of the Panama Canal, $50 \mathrm{~km}$ North of Panama City, the capital city for the Republic of Panama. Buenos Aires and Agua Bendita had an estimated population of 6020 people in year 2000 , considered to be $15 \%$ of the total population in Chilibre County. The first settlements were established 60 years ago, mostly for Panama Canal workers. Thirty years ago, a study in the Chilibre region described the domestic and peridomestic presence of $R$. pallescens with high natural trypanosome infection rates ${ }^{24}$. No up-todate information regarding the prevalence of triatomine natural infection rates or human trypanosomiasis in this region is available.

Eco-epidemiological information gathered from the survey contemplated the evaluation of Chagas disease risk factors, including the presence of vegetation and palm trees near houses, and the presence of domestic and sylvatic animals in the area. Other epidemiological data such as housing facilities, time of residency in the area, and knowledge about the disease and its vector were also investigated.

Vectors: Direct search for triatomines was made inside and around houses as well as in sylvatic ecotopes. Community participation was valuable for collecting triatomines within the domestic and peridomestic habitats, especially at night. Sylvatic triatomines were collected from dissected palm trees near the surveyed houses by our field workers. The number, stages and location of the collected triatomine were recorded. All hand-collected triatomines were taken to the laboratory facilities in plastic containers with filter paper for proper identification using a standard reference key. Salivary glands and rectal ampoule content from collected specimens were placed on physiological saline and then microscopically examined for the presence of parasites. A combined intestine-rectum sample from trypanosome positive vectors was intraperitoneally inoculated into susceptible white mice (CFW). Twentyone days post inoculation the animals were bled by cardiac puncture and the whole blood was cultured into modified Senekjie's biphasic medium overlaid with either saline or $10 \%$ FCS Scheinder's medium. Cultures were microscopically examined for the presence of trypanosomes for at least a 2-month period. Massive replication of the isolated parasites was achieved and lysates were stored at $-20{ }^{\circ} \mathrm{C}$ for further characterization.

Trypanosome isolates: Isolated trypanosomes were characterized by means of isoenzyme electrophoresis on cellulose acetate membranes as previously described ${ }^{8}$. The following three systems were used: PGM 2.7.5.1 (phosphoglucomutase), ALAT 2.6.1.1 (alanine aminotransferase) and ASAT 2.6.1.1 (aspartate aminotransferase). Isoenzyme profiles were then phylogenetically grouped using the TAXAN PROGRAM (Information Resources Group, Maryland Biotechnology Institute, University of Maryland). Local reference strains for the present study were: H.I.R. 116-B-Clon 4 (T. cruzi reference strain for Panama) and T.r./HLN/75/c12 (T. rangeli reference strain for Panama).

Precipitin test: As epidemiological complementary information, feeding patterns of the insects blood sources were determined by the precipitin test ${ }^{2,3}$.

Anti-T. cruzi antibodies assessment: During the first year of the study, blood samples were randomly collected from people living in the surveyed houses. Anti-T. cruzi antibodies were determined by Indirect Immunofluorescence (IIF). For the second year of the study, serological tests were performed only on residents from houses where triatomines were seen or captured. Positive sera samples were confirmed by ELISA (Wiener ELISA Chagas test) and Western Blot tests ${ }^{18}$. Additional searches for triatomines were carried out in these homes and peridomiciliary sites.

Statistical analysis: Statistical analyses were performed using the Epi Info 6 program. Significance of differences was verified using the Chi-square test.

\section{RESULTS}

A total of 716 houses in the Chilibre County, 368 from Buenos Aires and 348 from Agua Bendita were surveyed. Houses in these two areas accounted for 3122 people (1581 from Buenos Aires and 1541 from Agua Bendita). There was a mean of 4.4 people living in each house. Sex and age distribution was similar between the two studied sites. Mean residency in the area was 22 years.

The population's knowledge of Chagas disease and its vector was assessed. Half $(51.8 \%)$ of the people surveyed recognized triatomines as vectors of Chagas disease transmission, however, no statistical significant difference was found between the two areas studied (54.9\% Buenos Aires vs 48.5\% Agua Bendita, $\mathrm{p}=0.22$ ).

Housing facilities have been subject to constant improvement, especially during the last few years, thus affecting Chagas disease 
epidemiology in the region. If the two study sites are considered as a whole, $86.4 \%(n=619)$ of the total houses surveyed $(n=716)$ were made of cement with a galvanized roof, $10.1 \%(n=72)$ were made of mixed construction materials and $3.5 \%(n=25)$ were of natural material (palm thatch roof and cane walls) (Table 1). A significant difference was found between the housing facilities in the two studied sites $(p=0.00036)$. Buenos Aires had poorer housing conditions with a greater number of houses built of natural materials.

\section{Table 1}

Total number and type of housing facilities in two periurban neighborhoods, Community of Chilibre, Panama, 1999-2000

\begin{tabular}{lcccc}
\hline Area & Total & $1 *$ & $2 * *$ & $3 * * *$ \\
\hline Buenos Aires & 368 & $302(82.1 \%)$ & $45(12.2 \%)$ & $21(5.7 \%)$ \\
Agua Bendita & 348 & $317(91.1 \%)$ & $27(7.8 \%)$ & $4(1.1 \%)$ \\
Total & 716 & $619(86.4 \%)$ & $72(10.1 \%)$ & $25(3.5 \%)$ \\
\hline
\end{tabular}

$1 *$ Houses made of cement and galvanized roof; $2 * *$ Houses made of mixed materials (wood, galvanized or occasionally palm thatch roof); $3 * * *$ Houses made of natural materials (palm thatch roof and walls and dirt floor).

Most houses at both study sites $(95 \%)$ were surrounded by haulm and secondary forest less than 20 meters from the house. Among the remaining secondary forest present in the area, A. butyracea was predominant. Since the principal vector of $T$. cruzi and T. rangeli in Panama, $R$. pallescens, is primarily associated with palm tree habitat ${ }^{25}$, ${ }^{26}$, the proximity of houses to the A. butyracea, was evaluated as a risk factor $^{20}$. In Buenos Aires, 51.6\% (190/368) and in Agua Bendita 31.3\% $(109 / 348)$ of the houses had palm trees less than 100 meters from the houses (Table 2). A significant difference was found when comparing the presence of palm trees near the houses at the two studied sites $(\mathrm{p}=$ $0.015)$.

Table 2

Presence of palm trees near houses in two periurban neighborhoods, community of Chilibre, Panama, 1999-2000

\begin{tabular}{lcccc}
\hline Area & Positive vs total & \multicolumn{3}{c}{ Distance from houses } \\
& number of houses & $<10 \mathrm{~m}$ & $20-100 \mathrm{~m}$ & $>100 \mathrm{~m}$ \\
\hline Buenos Aires & $223 / 368(60.6 \%)$ & 40 & 150 & 33 \\
Agua Bendita & $138 / 348(39.7 \%)$ & 11 & 98 & 29 \\
Total & $361 / 716(50.4 \%)$ & 51 & 248 & 62 \\
\hline
\end{tabular}

The role which sylvatic and domestic animals participate in the transmission of $T$. cruzi has not been well established at the study sites.
Sylvatic animals were common at both sites (Table 3). Opossums, considered to be the main reservoir host for T. cruzi in Panama, were among the most common sylvatic animals seen ${ }^{4,23}$. Domestic animals were also frequent in both locations; dogs were predominant $(62 \%)$, followed by fowls $(55.1 \%)$ and cats $(20.7 \%)$. Fowls were usually kept loose in the yard. No significant difference regarding domestic or sylvatic animal distribution between both study sites was observed.

\section{Table 4}

Age and sex distribution as per microhabitat of Rhodnius pallescens collected in two periurban neighborhoods, Community of Chilibre, Panama, 1999-2000

\begin{tabular}{lcccr}
\hline$R$. pallescens & Intradomicile & Peridomicile & Palm trees & Total \\
\hline Adults & 32 & 27 & 324 & 383 \\
Male & 11 & 14 & 192 & 217 \\
Female & 21 & 13 & 132 & 166 \\
Nymph stages & 0 & 0 & 626 & 626 \\
$1^{\text {st }}$ & - & - & 45 & 45 \\
$2^{\text {nd }}$ & - & - & 212 & 212 \\
$3^{\text {rd }}$ & - & - & 173 & 173 \\
$4^{\text {th }}$ & - & - & 121 & 121 \\
$5^{\text {th }}$ & - & - & 75 & 75 \\
Not specified & & & 100 & 100 \\
Total & 32 & 27 & 1050 & 1109 \\
\hline
\end{tabular}

Sixty three palm trees were felled and totally dissected in search of triatomine bugs. Of the 48 palm trees from Buenos Aires, 75\% (36/48) were found to be positive for triatomines, while in the area of Agua Bendita, $93.3 \%$ (14/15) were colonized by the insect. An overall of 50/ 63 palm tress were found to be positive for $R$. pallescens (infestation index rate $=79.4 \%$ ). Two coconut palms trees were also examined, but no triatomines were observed. An additional palm tree specie, Acrocomia aculiata, resulted positive for $R$. pallescens nymph and adult stages, though few in numbers. Animals or animal nests were found in $68 \%$ (34/50) of the triatomine positive palm trees, $75 \%$ in Buenos Aires and $50 \%$ in Agua Bendita.

Of the 1109 triatomines collected for the present study during 1999 and 2000, 32 (2.9\%) were collected inside houses, close to the light at night, while $27(2.4 \%)$ were found crawling around the houses. The remaining 1050 collected triatomines $(94.7 \%)$ were hand captured from palm trees (Table 4). All specimens were identified as $R$. pallescens, except for one identified as Panstrongylus rufotuberculatus, found resting on an outside wall of a house at the Buenos Aires study site. The latter is considered a sylvatic vector. Only adult triatomines were collected inside or around houses, no immature stages were found inside houses in either

Table 3

Presence of sylvatic animals in two periurban neighborhoods, Community of Chilibre, Panama, 1999-2000

\begin{tabular}{|c|c|c|c|c|c|c|}
\hline \multirow{2}{*}{ Area } & \multirow{2}{*}{$\begin{array}{l}\text { Positive vs total number } \\
\text { of houses }\end{array}$} & \multicolumn{5}{|c|}{ Sylvatic animals } \\
\hline & & Opossum & Mice & Bats & Monkeys & Other* \\
\hline Buenos Aires & $346 / 368(94.0 \%)$ & 240 & 250 & 294 & 62 & 203 \\
\hline Agua Bendita & $324 / 348(92.8 \%)$ & 215 & 254 & 291 & 59 & 269 \\
\hline Total & $670 / 716(93.6 \%)$ & 456 & 505 & 566 & 122 & 266 \\
\hline
\end{tabular}

* Included armadillo, sloths and squirrels. 


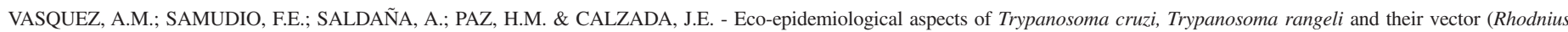
pallescens) in Panama. Rev. Inst. Med. trop. S. Paulo, 46(4):217-222, 2004

of the two study sites. In contrast, all triatomine stages of $R$. pallescens were collected from palm trees, indicating a $100 \%$ colonization index rate (Table 4). Sex and age distribution of R. pallescens collected on palm trees were similar for both study sites.

Salivary glands from $380 R$. pallescens were examined under the microscope for the presence of trypanosomes, 29 resulted positive (natural infection rate $=7.6 \%$ ). Rectal ampoule content from 373 triatomines were also examined; active trypanosomes were seen in 168 of them (natural infection rate $=45 \%$ ). Unfortunately, almost all triatomines collected inside and around houses at night by people from the community were too dry when handled by our team, therefore was not possible to assess infection in these specimens. Trypanosomes were recovered from 103 positive triatomines through mice inoculation and blood culture. Isoenzyme profiles proved that $85.4 \%(\mathrm{n}=88)$ of isolated trypanosomes were identified as $T$. cruzi and $14.6 \%(\mathrm{n}=15)$ as $T$. rangeli.

As a complement to epidemiological studies, blood meal analysis was performed in 829 R. pallescens. Of these, 466 (56.2\%) contained sufficient blood for host identification. Mammalian feedings accounted for most of the blood sources (95.9\%). Marsupials (opossums) were by far the preferential mammalian blood source $(82.6 \%)$. Specimens feeding on bats $(2.8 \%)$, sloths $(0.8 \%)$ and man $(0.4 \%)$ were also identified. Only $2.3 \%$ of all processed specimens fed on birds or reptiles and less than $2 \%$ fed on more than one animal (Table 5).

\section{Table 5}

Precipitin blood meal analysis on collected Rhodnius pallescens from two periurban neighborhoods, Community of Chilibre, Panama, 1999-2000

\begin{tabular}{lcc}
\hline Blood source & Number & $\%$ \\
\hline Mammalian & 43 & \\
Undetermined & 2 & 9.2 \\
Hominidae & 13 & 0.4 \\
Chiroptera & 385 & 2.8 \\
Didelphidae & 4 & 82.6 \\
Bradypodidae & 447 & 0.8 \\
Sub-total & & 95.9 \\
& 6 & \\
Avian & & 1.3 \\
& & \\
Reptilian & 1 & 0.2 \\
Undetermined & 3 & 0.6 \\
Sauria & 1 & 0.2 \\
Serpentelia & & \\
& & \\
Double feeding & 2 & 0.4 \\
Didelphidae + Myrmecophagidae & 5 & 1.1 \\
Didelphidae + Avian & 1 & 0.2 \\
Mammalian + Amphibian & & \\
Analyzed samples & 466 & \\
Insufficient or digested blood & 363 & \\
Total & 829 & \\
\hline
\end{tabular}

During the first year of the study serology by IIF demonstrated that $7(3.1 \%)$ of 222 samples randomly collected from people living in the study area, presented antibodies against $T$. cruzi. Positive samples included five females and two males older than 28 years with serum titers ranging from 1.40 to $1: 160$. People sampled during the second year of the study were those living in houses where triatomines had previously been captured inside or around the house, and thus considered to be at high-risk. A total of 151 samples were collected from both neighborhoods, 135 samples from Buenos Aires and 16 samples from Agua Bendita. Seropositivity by IIF was detected in 7 (5.2\%) people from Buenos Aires and in one (6.2\%) person from Agua Bendita, indicating an overall seroprevalence of $5.3 \%$. However, when these positive IIF samples $(n=8)$ were evaluated by ELISA using recombinant antigen and Western blot analysis, only three samples were positively confirmed, thus lowering the seroprevalence to $1.9 \%$.

\section{DISCUSSION}

The process of increasing urbanization and expansion of agricultural frontiers into sylvatic areas might generate new public health problems in Panama. The migrating population is at high risk for contracting a vector borne disease, such as Chagas disease. Both study sites are next to the Panama Canal Reserve Primary Forest and were once part of this reserve. The presence of a great number of wild animals in the area is in fact, an indicator of the proximity to primary forest. The area is undergoing significant ecological changes. Primary forest has been destroyed due to constant human migration and colonization.

Our findings from collected triatomines confirmed that despite all changes in the ecotope, the previous reports indicating that $R$. pallescens is the triatomine most frequently found in Central Panama continue to be valid $^{12,13} . R$. pallescens is considered sylvatic, we have not found any evidence demonstrating that this insect has become domiciliated in Panama. More than 30 years ago, a previous study, however, showed evidence of possible domiciliation of $R$. pallescens in certain locations of Central Panama ${ }^{17}$. The domiciliation trend of this triatomine has not been recently evaluated in areas with poor housing facilities, although it is an important issue to resolve due to the potential epidemiological risk for transmission of the infection to people living in infested houses. For the present study, most triatomines were hand collected from palm trees $(n=1050)$, their natural sylvatic ecotope. We did find $R$. pallescens inside $(\mathrm{n}=33)$ and/or around the surveyed houses $(n=27)$, but no nymph stages were found. It is well known that triatomine species can be attracted at night to visible and UV light sources. Thus, considering the close proximity of palm trees to houses, domestic and peridomestic finding of triatomines in dwellings from this area may simply be an occasional or chance event.

Despite all changes in the area we found, in agreement with a previous report $^{24}$, a high natural trypanosome infection rate in $R$. pallescens collected from peridomestic and sylvatic habitats (palm trees). T. cruzi was found in most of the isolated trypanosomes (85.4\%), whilst $T$. rangeli was identified in $14.6 \%$ of the samples. Though the use of three different isoenzyme systems was sufficient to separate $T$. cruzi from $T$. rangeli, further biochemical and molecular studies are in progress to identify possible T. cruzi variants found in the area. Results from this work will be published later.

Results from the present study confirmed that $R$. pallescens is a zoophilic vector, feeding mainly from sylvatic mammals. As in previous reports, we also found that opossums are the preferred blood source of 


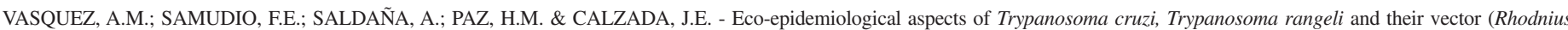
pallescens) in Panama. Rev. Inst. Med. trop. S. Paulo, 46(4):217-222, 2004.

$R$. pallescens, and more likely continues to be the reservoir host responsible for maintenance of the sylvatic cycle of $T$. cruzi in the area.

More than 20 years ago, triatomines examined by blood meal analysis from three rural communities in central Panama province, also demonstrated their preference for wild mammals as blood source, although in that report slightly less than half of the collected triatomines had fed on humans ${ }^{3}$. In the present study, using the same procedure, hominidae feeding was only detected in two insects. The abundance of sylvatic animals in the area has contributed to maintain $R$. pallescens within its own natural ecotope, because blood sources from wild animals are sufficiently abundant to meet their requirements. On the other hand, the continuous improvement of housing facilities observed in these areas has probably limited potential triatomine domiciliation.

A small number of huts with thatched roofs remain in the area. However, most of the houses in these communities are now constructed of materials which are not suitable for triatomine breeding and survival. This means that an important control of Chagas disease transmission in the area might have arisen spontaneously with the social evolution of people and better overall living standards.

Despite the close proximity of houses to palm trees highly colonized by $R$. pallescens infected with $T$. cruzi, the seroprevalence in humans was relatively low (less than $2 \%$ ), specially when IIF positive samples were further tested with two additional serological assays, as recommended by the World Health Organization (WHO). Serological tests for $T$. cruzi infections are considered highly sensitive, but their specificity has been questioned due to antigenic cross-reactivity with other parasites, such as Leishmania and T. rangeli ${ }^{11,18,21}$. Both trypanosome species ( $T$. cruzi and $T$. rangeli) are circulating in the area, and cutaneous leishmaniasis is also endemic, suggesting a high possibility for false-positive results when a single serological test is used.

Characteristics of Chagas disease in Panama are different from those clinical manifestations seen in most South American countries. There is no record of megatube inductions, parasitemia in man is of relatively short duration and the chronic phase seems to be more benign ${ }^{23}$. In fact, during the two years of the study there were few reports of people with clinical manifestations associated to Chagas disease. It is worth mentioning that Chagas disease assumes its mildest form in countries such as Panama, where vectors of the disease, especially $R$. pallescens, have high $T$. rangeli infection rates, a parasite thought to be entirely non-pathogenic to humans. For endemic regions in Panama, T. rangeli is more frequently found in human blood than $T$. $c r u z i^{23}$. In this sense, recent data have shown that complete or partial immunity against $T$. cruzi can be obtained in animal models previously immunized with low virulent $T$. cruzi strains ${ }^{5,9}$ or with $T$. rangeli ${ }^{1,29}$. The fact that more than one $T$. cruzi strain $^{10,16}$ and even more than one Trypanosoma species ${ }^{6,23}$ can be transmitted by $R$. pallescens in Panama makes this possibility feasible. Undoubtedly, this hypothesis needs to be further evaluated and other aspects responsible for the large spectrum of Chagas disease manifestations, such as host genetic factors and local T. cruzi isolates virulence, should also be taken into consideration.

Our results demonstrate that in the area under study, T. cruzi survives in a balanced association with $R$. pallescens and with several species of mammals in its natural niches. However, ecological changes such as deforestation may cause mortality amongst the sylvatic vertebrate hosts, leading to poor nutritional status of their associated triatomines and inducing the insect to seek other blood sources in new habitats. Samples of domiciliation in periurban and intradomicilary areas, in which sylvatic triatomines had become adapted to alternative food sources, have been recently described in neighboring countries ${ }^{19,27}$.

Under the above described ecological conditions, human T. cruzi transmission within the Chilibre Community is low. The fact that $50 \%$ of the population is aware of the presence of the vector, and that there is a tendency to kill the bug as soon as it is seen flying into the house, may have contributed to control triatomine colonization of dwellings. However, taking into consideration that the population is at real and imminent risk of infection, it is important to implement a community educational program, regarding both the disease and control measures. Periodic entomological surveillance to monitor vector population and possible domestic triatomine foci are also necessary.

\section{RESUMO}

\section{Generalidades do Trypanosoma cruzi, do Trypanosoma rangeli e do seu vetor (Rhodnius pallescens) no Panamá}

A epidemiologia da infecção do T. cruzi foi investigada na margem oriental do canal do Panamá, na região central da Republica do Panamá. A informação obtida durante o estudo avaliou fatores de risco da doença de Chagas nesta área. Entre 1999 e 2000, 1110 triatomíneos foram coletados: 1050 triatomíneos $(94,6 \%)$ em palmeiras, $27(2,4 \%) \mathrm{em}$ habitats periurbanos e $33(3,0 \%)$ no interior de casas. Todos os espécimens foram identificados como $R$. pallescens. Não havia nenhuma evidência de domiciliação do vetor. O exame de glândulas salivares de $380 R$. pallescens revelaram taxa de infecção natural por Trypanosoma de $7,6 \%$, mas o conteúdo da ampola rectal de 373 triatomíneos mostrou $45 \%$ de positividade. Os perfis de isoenzimas em Trypanosomas isolados demonstraram que $85,4 \%(\mathrm{n}=88)$ eram $T$. cruzi e $14,6 \%(\mathrm{n}=15)$ eram T. rangeli. A análise da refeição de sangue de $829 R$. pallescens demonstrou comportamento zoofílico do vetor, sendo os gambás a fonte preferencial de sangue. Soroprevalência nos seres humanos de ambos locais de estudo foi menos que $2 \%$. Nossos resultados demonstram que T. cruzi sobrevive na área em associação equilibrada com $R$. pallescens e com diversas espécies diferentes de mamíferos em seus nichos naturais. Entretanto, a área é um risco eminente de infecção para sua população, pelo que é importante executar um programa educacional na comunidade a respeito das medidas, do conhecimento e do controle da doença.

\section{ACKNOWLEDGEMENTS}

We are grateful to Salomón Puga, Roberto Rojas, Jorge Aparicio, and Jose Montenegro for the excellent field and technical work put into the project.

The present investigation received partial financial support from UNDP/WORLD BANK/WHO Special Programme for Research and Training in Tropical Diseases (TDR). Ref: T80/181/167 ID 980288. 


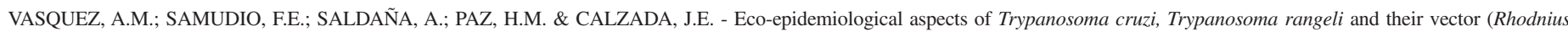
pallescens) in Panama. Rev. Inst. Med. trop. S. Paulo, 46(4):217-222, 2004.

\section{REFERENCES}

1. BASSO, B.; MORETTI, E.R. \& VOTTERO, C.E. - Immune response and Trypanosoma cruzi infection in Trypanosoma rangeli-immunized mice. Amer. J. trop. Med. Hyg., 44: 413-419, 1991.

2. CHRISTENSEN, H.A.; SOUSA, O.E. \& DE VASQUEZ, A.M. - Host feeding profiles of Triatoma dimidiata in peridomestic habitats of western Panama. Amer. J. trop. Med. Hyg., 38: 477-479, 1988.

3. CHRISTENSEN, H.A \& DE VASQUEZ, A.M. - Host feeding profiles of Rhodnius pallescens (Hemiptera: Reduviidae) in rural villages of Central Panama. Amer. J. trop. Med. Hyg., 30: 278-283, 1981.

4. CHRISTENSEN, H.A; WHITLAW Jr., J.T.; CHANIOTIS, B.N. \& DE VASQUEZ, AM. - Sylvatic hosts of Rhodnius pallescens (Hemiptera: Reduviidae) nymphs in the Panama Canal Zone. J. med. Entomol., 17: 182, 1980.

5. GOMEZ, L.E.; NASSER, J.R. \& BASOMBRIO, M.A. - Complete immunization against Trypanosoma cruzi verified in individual mice by complement-mediated lysis. Mem. Inst. Oswaldo Cruz, 91: 55-61, 1996.

6. GUHL, F.; HUDSON, L.; MARINKELLE, C.J.; JARAMILLO, C.A. \& BRIDGE, D. Clinical Trypanosoma rangeli infection as a complication of Chagas' disease. Parasitology, 94: 475-484, 1987.

7. KIRCHHOFF, L.V. - American trypanosomiasis (Chagas' disease) a tropical disease now in the United States. New Engl. J. Med., 329: 639-644, 1993.

8. KREUTZER, R.D. \& SOUSA, O. - Biochemical characterization of Trypanosoma spp. by isozyme electrophoresis. Amer. J. trop. Med. Hyg., 30: 308-317, 1981.

9. LAURIA-PIRES, L. \& TEIXEIRA, A.R. - Protective effect of exposure to non-virulent Trypanosoma cruzi clones on the course of subsequent infections with highly virulent clones in mice. J. comp. Path., 117: 119-126, 1997.

10. LAURIA-PIRES, L. \& TEIXEIRA, A.R. - Virulence and pathogenicity associated with diversity of Trypanosoma cruzi stocks and clones derived from Chagas' disease patients. Amer. J. trop. Med. Hyg., 55: 304-310, 1996.

11. MALCHIODI, E.L.; CHIARAMONTE, M.G.; TARANTO, N.J.; ZWIRNER, N.W. \& MARGNI, R.A. - Cross-reactivity studies and differential serodiagnosis of human infections caused by Trypanosoma cruzi and Leishmania spp; use of immunoblotting and ELISA with a purified antigen (Ag163B6). Clin. exp. Immunol., 97: 417-423, 1994.

12. MÉNDEZ, E. \& SOUSA, O.E. - Identificación y distribución de los triatominos de Panamá (Hemiptera: Reduviidae: Triatominae). Rev. med. Panamá, 4: 258-280, 1979.

13. MÉNDEZ, E.; SOUSA, O.E. \& TURNER, A.Y. - Caracterización biológica y ecológica de los triatominos panameños (Hemiptera: Reduviidae). Scientia, 12: 7-66, 1997.

14. MILLER, J.W. - Chagas'disease in Panama: report of 3 cases. Sth. med. J., 24: 645-647, 1931.
15. MINISTERIO DE SALUD, Centro de Investigación para el Control de Enfermedades (CICEN), Panama. Bol. Inf., 22(12), 1998.

16. MONTAMAT, E.E.; DE LUCA D’ORO, G.M.; GALLERANO, R.H.; SOSA, R. \& BLANCO, A. - Characterization of Trypanosoma cruzi populations by zymodemes: correlation with clinical picture. Amer. J. trop. Med. Hyg., 55: 625-628, 1996.

17. PIPKIN, A.C. - Domiciliary reduviid bugs and the epidemiology of Chagas'disease in Panama (Hemiptera:Reduviidae:Triatominae). J. med. Entomol., 5: 107-124, 1968

18. REICHE, E.M.; CAVAZZANA Jr., M.; OKAMURA, H. et al. - Evaluation of the Western blot in the confirmatory serologic diagnosis of Chagas' disease. Amer. J. trop. Med. Hyg., 59: 750-756, 1998.

19. REYES-LUGO, M. \& RODRIGUEZ-ACOSTA, A. - Domiciliation of the sylvatic Chagas disease vector Panstrongylus geniculatus Latreille, 1811 (Triatominae: Reduviidae) in Venezuela. Trans. roy. Soc. trop. Med. Hyg., 94: 508, 2000.

20. ROMAÑA, C.A.; PIZARRO, J.C.; RODAS, E. \& GUILBERT, E. - Palm trees as ecological indicators of risk areas for Chagas' disease. Trans. roy. Soc. trop. Med. Hyg., 93: 594-595, 1999.

21. SALDAÑA, A. \& SOUSA, O.E. - Trypanosoma rangeli: epimastigote immunogenicity and cross-reaction with Trypanosoma cruzi. J. Parasit., 82: 363-366, 1996.

22. SCHOFIELD, C.J. \& DIAS, J.C. - The Southern Cone initiative against Chagas disease. Advanc. Parasit., 42: 1-27, 1999.

23. SOUSA, O.E. - Anotaciones sobre la enfermedad de Chagas en Panamá. Frecuencia y distribución de Trypanosoma cruzi y Trypanosoma rangeli. Rev. Biol. trop., 20: 167-169, 1972.

24. SOUSA, O.E. \& JOHNSON, C.M. - Prevalence of Trypanosoma cruzi and Trypanosoma rangeli in triatomines (Hemiptera: Reduviidae) collected in the Republic of Panama. Amer. J. trop. Med. Hyg., 22: 18-23, 1973.

25. WHITLAW, J.T. \& CHANIOTIS, B.N. - Palm trees and Chagas' disease in Panama. Amer. J. trop. Med. Hyg., 27: 873-881, 1978.

26. WHITLAW, J.T. - Palm trees and disease. Int. J. Derm., 19: 142-143, 1980.

27. WOLFF, M. \& CASTILLO, D. - Domiciliation trend of Panstrongylus rufotuberculatus in Colombia. Mem. Inst. Oswaldo Cruz, 97: 297-300, 2002.

28. WORLD HEALTH ORGANIZATION - Control of Chagas disease. Wld. Hith. Org. techn. Rep. Ser., (905): 1-109, 2002.

29. ZUNIGA, C.; PALAU, T.; PENIN, P.; GAMALlO, C. \& DE DIEGO, J.A. - Protective effect of Trypanosoma rangeli against infections with a highly virulent strain of Trypanosoma cruzi. Trop. Med. Int. HIth., 2: 482-487, 1997.

Received: 26 January 2004

Accepted: 12 July 2004 